\title{
Factors Associated with Success Rate of Vaginal Birth after One Caesarean Section (VBAC) in Ibrahim Malik Teaching Hospital, Khartoum-Sudan
}

\author{
Bashir J A ${ }^{1}$, Noureldin $\mathrm{K}^{2}$, Elhassan MAY ${ }^{3}$, \\ Abdelwahid MA $^{4}$ and Handady MOS ${ }^{5 *}$ \\ ${ }^{1}$ Department of Obstetrical \& Gynecology, Omdurman \\ Maternity Hospital, Sudan \\ ${ }^{2}$ Assistant Professor of Obstetrical \& Gynecology, Faculty \\ of Medicine University of Khartoum, Sudan \\ ${ }^{3}$ Faculty of Medicine \& Health Sciences, University of \\ Kordofan, Sudan \\ ${ }^{4}$ Assistant Professor of Obstetrics and Gynecology, \\ Faculty of Medicine, Al Neelain University, Sudan \\ ${ }^{5}$ Associated Professor of Obstetrics and Gynecology, \\ NAHDA Colleague, Khartoum, Sudan \\ *Corresponding author: Siddig Omer M Handady, \\ Associated Professor of Obstetrics and Gynecology, \\ NAHDA Colleague, Khartoum, Sudan
}

Received: November 23, 2018; Accepted: December 06, 2018; Published: December 13, 2018

\begin{abstract}
Objectives: To determine success rate of VBAC (Vaginal Birth after Cesarean Section) with reference to prognostic factors to predict successful VBAC in Ibrahim Malik Teaching Hospital- Khartoum-Sudan.

Methodology: It was observational, cross sectional and hospital based study conducted between (January-December 2015), involving 342 pregnant women with one previous $\mathrm{C} / \mathrm{S}$ who were admitted in the labor room as emergency cases, were evaluated thoroughly, data collected through designed questionnaire include:- Socio-demographic characters, antenatal clinic follow up, previous $\mathrm{C} / \mathrm{S}$, variables affect success of VBAC and outcome of current pregnancy.

Results: Among 342 pregnant women involved in this study, (67.3\%) had successful VBAC, while $112(32.7 \%)$ had emergency caesarean section. The majority of women $286(83.6 \%)$ were counseled for VBAC. Fetal distress was the most common cause for previous C/S 134 (39.2\%) and failure to progress account for $53(15.5 \%)$. Factors affecting success rate of the VBAC in this study were; BMI between $25-30$ was (67.8\%), previous successful VBAC was (54.3) \% and birth weight between 3.6-4 kg was (56.5\%). Women who had an emergency caesarean section in their first birth also had a lower VBAC success rate, particularly those with a history of failure to progress as main indication for the primary caesarean section.
\end{abstract}

Conclusion: This study reported (67.3\%) success rate of VBAC and concludes a significant increase in the successful rate of VBAC associated with accurate prior ante natal care, meticulous counseling, prior vaginal delivery, previous success VBAC, BMI between $25-30$ and maternal age $<35$ years.

Keywords: VBAC; Success rate; Prognostic factors; Khartoum-sudan

\section{Introduction}

Previous caesarean section has been found to be the commonest cause of increased caesarean section rate in many parts of the world [1]. Because of increased risk of maternal complications with repeat caesarean section and safety of VBAC, trial of labor for selected group of patients with previous scar has become a preferred strategy [2].

The majority of women with an uncomplicated first caesarean section, in an otherwise uncomplicated pregnancy, are candidates for attempting VBAC [3-4]. Although attempts at a vaginal birth after a cesarean section (VBAC) become accepted practice, successful vaginal birth after cesarean delivery (VBAC), as well as the rate of attempted VBACs, has decreased during the past 10 year.

According to the World Health Organization (WHO) in 2015, CS rates in women who had a previous CS ranged between 78.1 and $79.4 \%$ in high-income countries, 85.2 and $87.5 \%$ in middle-income countries and 63.2 and $72.1 \%$ in low-income countries [5]. In subSaharan African countries, successful vaginal delivery in women with VBAC in these countries stood at 70-80\% [5-7]. Even those factors found to be associated with successful VBAC vary from centre to centre. However, this study attempts to highlight the various factors which have a prognostic significance for success of VBAC in Ibrahim Malik Teaching Hospital in Sudan.

\section{Materials and Methods}

It was observational, cross sectional and hospital based study conducted during one year (January-December 2015) at Ibrahim Malik Hospital. Khartoum- Sudan. The hospital offer Vaginal Birth After Caesarean Section (VBAC) based on the RCOG recommendations, if the women fulfill the following criteria: mother counseling, plan, accept and consent for VBAC, the mother has one previous lower uterine segment scar, non-recurring previous indications, singleton pregnancy, cephalic presentation, estimated fetal weight less than or equal to $4 \mathrm{~kg}$, not pass her date and no current indication for caesarean section. About 342 patients with one previous $\mathrm{C} / \mathrm{S}$, fulfill the inclusion criteria for (VBAC) admitted in the labor room as emergency cases during the study period were evaluated thoroughly.

A detailed history regarding previous and current pregnancies were reviewed, including indications for prior cesarean section, type of $\mathrm{C} / \mathrm{S}$, type of uterine scar, a history of prior vaginal delivery, birth
Austin J Obstet Gynecol - Volume 5 Issue 9 - 2018

Submit your Manuscript | www.austinpublishinggroup.com

Handady et al. () All rights are reserved
Citation: Bashir JA, Noureldin K, Elhassan MAY, Abdelwahid MA and Handady MOS. Factors Associated with Success Rate of Vaginal Birth after One Caesarean Section (Vbac) in Ibrahim Malik Teaching Hospital, Khartoum-Sudan. Austin J Obstet Gynecol. 2018; 5(9): 1129 
Table 1: VBAC and demographic data with significance table and the $p$ value among respondents.

\begin{tabular}{|c|c|c|c|c|}
\hline \multicolumn{2}{|c|}{ Variable } & \multirow{2}{*}{$\begin{array}{c}\text { Success rate } 230(\mathbf{6 7 . 3} \%) \\
31(13.5 \%)\end{array}$} & \multirow{2}{*}{$\begin{array}{c}\text { Failure rate } 112 \mathbf{( 3 2 . 7 \% )} \\
13(11.6 \%)\end{array}$} & $P$ value \\
\hline \multirow{5}{*}{ Age } & $<20$ years & & & \multirow{5}{*}{$002^{*}$} \\
\hline & $20-30$ years & $114(49.6 \%)$ & $41(36.6 \%)$ & \\
\hline & $31-40$ years & $72(31.3 \%)$ & $31(27.7 \%)$ & \\
\hline & $>40$ years & $13(05.6 \%)$ & $27(24.1 \%)$ & \\
\hline & Total & $230(100.0 \%)$ & $112(100.0 \%)$ & \\
\hline \multirow{3}{*}{ Antenatal care } & Regular & $147(63.9 \%)$ & $46(41.1 \%)$ & \multirow{3}{*}{$000^{*}$} \\
\hline & Irregular & $83(36.1 \%)$ & 66 (58.9\%) & \\
\hline & Total & $230(100.0 \%)$ & $112(100.0 \%)$ & \\
\hline \multirow{4}{*}{ Gravidity } & 2 & $86(37.4 \%)$ & $39(34.8 \%)$ & \multirow{5}{*}{$0.03^{*}$} \\
\hline & $3-4$ & $104(45.2 \%)$ & $40(35.7 \%)$ & \\
\hline & 5 and more & $40(17.4 \%)$ & $33(29.5 \%)$ & \\
\hline & Total & $230(100.0 \%)$ & $112(100.0 \%)$ & \\
\hline \multirow{5}{*}{ Education level } & Illiterates & $05(02.2 \%)$ & $06(05.4 \%)$ & \\
\hline & Primary & $35(15.2 \%)$ & $18(16.1 \%)$ & \multirow{4}{*}{0.123} \\
\hline & Secondary & $172(74.8 \%)$ & $60(53.5 \%)$ & \\
\hline & University & $18(07.8 \%)$ & $28(25.0 \%)$ & \\
\hline & Total & $230(100.0 \%)$ & $112(100.0 \%)$ & \\
\hline \multirow{4}{*}{ Socioeconomic status } & Low & $129(56.1 \%)$ & $50(44.6 \%)$ & \multirow{4}{*}{0.087} \\
\hline & Moderate & $88(38.3 \%)$ & $42(37.5 \%)$ & \\
\hline & High & $13(05.6 \%)$ & $20(17.9 \%)$ & \\
\hline & Total & $230(100.0 \%)$ & $112(100.0 \%)$ & \\
\hline \multirow{3}{*}{ Counseling for VBAC } & Yes & $221(96.1 \%)$ & $65(58.1 \%)$ & \multirow{3}{*}{$0.01^{*}$} \\
\hline & No & $09(03.9 \%)$ & $47(41.9 \%)$ & \\
\hline & Total & $230(100.0 \%)$ & $112(100.0 \%)$ & \\
\hline
\end{tabular}

*Statistically significant at 0.05 level.

weight of infant, inter pregnancy interval, puerperal complications in previous deliveries and etc.

The estimated birth weight of present infant, condition of scar and adequacy of pelvis were ascertained. Routine investigations like $\mathrm{CBC}$, Rh group etc., was carried out. Ultrasonography was carried out in all the patients to know the maturity of fetus, placenta localization and to rule out anomalies. The patients were carefully selected for vaginal trial of labor and were taught to recognize the basic signs and symptoms of labor as well as scar dehiscence or uterine rupture.

During labor, women were monitored using a partogram including fetal monitoring by (CTG) and regular prompting for vaginal bleeding, uterine tenderness.

Statistical analysis was performed via SPSS software (SPSS, Chicago, IL, USA). Continuous variables were compared using student's t test (for paired data) or Mann-Whitney U test for nonparametric data. For categorical data, comparison was done using Chi-square test (X2) or Fisher's Exact test when appropriate. A $P$ value of $<0.05$ was considered statistically significant.

Ethical clearance and approval for conducting this research was obtained from the general manager of the hospital and informed verbal consent was obtained from every respondent who agreed to participate in the study. Of course, the respondents informed that the study is not associated with experimental or therapeutic intervention while information was collected from her.

\section{Results}

The total number of mothers with one previous caesarean section who were offered Vaginal Birth after Caesarian Section (VBAC) and included in the study was 342 pregnant women involved in this study, (67.3\%) had successful VBAC, while (32.7\%) had emergency caesarean section.

Table 1 Shows that, the mean \pm SD of age was $25.7+3.1$ years, (67.8\%) of women were secondary educated, almost half of them were in low socioeconomic status and majority of patients (79.0\%) were multiparty between (2-4). Antenatal clinic follow up to 5 visits were 149 (43.6\%) and more than 5 visits were 193 (56.4\%).

Table 2 Shows VBAC and prognostic factors with significance table and the $\mathrm{p}$ value among respondents Indication of the previous caesarean section were fetal distress 134 (39.2\%), APH 28 (8.2\%), severe preeclampsia were $58(16.9 \%)$, failure to progress were 53 (15.5\%) and mal presentation were 40 (11.7\%). Caesarean section done emergency in 133 (38.9\%) and elective in 209 (61.1\%).

The body mass index less than 20 years were 20 (5.8\%) of women, between (20-25) were 192 (56.1\%), between (26-30) were 65 (19.1\%), 
Table 2: VBAC and prognostic factors with significance table and the $p$ value among respondents.

\begin{tabular}{|c|c|c|c|}
\hline VariaA1:D28ble & $\begin{array}{c}\text { Success rate } \\
230(67.3 \%)\end{array}$ & $\begin{array}{c}\text { Failure rate } 112 \\
(32.7 \%)\end{array}$ & $P$ value \\
\hline \multicolumn{4}{|c|}{ Indication of previous C/S } \\
\hline FD & $106(46.1 \%)$ & $28(25.1 \%)$ & \multirow{7}{*}{$0.00^{*}$} \\
\hline $\mathrm{APH}$ & $20(08.7 \%)$ & $08(07.1 \%)$ & \\
\hline Severe preeclampsia & $35(15.2 \%)$ & $23(20.5 \%)$ & \\
\hline Failure to progress & $28(12.2 \%)$ & $25(22.3 \%)$ & \\
\hline Mal presentation & $30(13.0 \%)$ & $10(08.9 \%)$ & \\
\hline Un known & $11(4.8 \%)$ & $18(16.1 \%)$ & \\
\hline Total & $230(100.0)$ & $112(100.0 \%)$ & \\
\hline \multicolumn{4}{|l|}{ Previous success VBAC } \\
\hline Yes & $125(54.3 \%)$ & $13(11.6 \%)$ & \multirow{3}{*}{$000^{*}$} \\
\hline No & $105(45.7 \%)$ & $99(88.4 \%)$ & \\
\hline Total & $230(100.0)$ & $112(100.0 \%)$ & \\
\hline \multicolumn{4}{|l|}{ BMI } \\
\hline$<20$ & $15(06.5 \%)$ & $05(04.5 \%)$ & \multirow{6}{*}{$0.00 *$} \\
\hline $20-25$ & $156(67.8 \%)$ & $36(32.1 \%)$ & \\
\hline $26-30$ & $45(19.6 \%)$ & $20(17.9 \%)$ & \\
\hline $31-35$ & $08(03.5 \%)$ & $18(16.1 \%)$ & \\
\hline$>35$ & $06(02.6 \%)$ & $33(29.4 \%)$ & \\
\hline Total & $230(100.0)$ & $112(100.0 \%)$ & \\
\hline \multicolumn{4}{|l|}{ Type of previous C/S } \\
\hline Emergency & $79(34.3 \%)$ & $54(48.2 \%)$ & \multirow{3}{*}{$0.02^{*}$} \\
\hline Elective & $151(65.7 \%)$ & $58(51.8 \%)$ & \\
\hline Total & $230(100.0)$ & $112(100.0 \%)$ & \\
\hline \multicolumn{4}{|l|}{ Fetal weight } \\
\hline $2.5-3 \mathrm{~kg}$ & 45 (19.6\%) & $16(14.3 \%)$ & \multirow{5}{*}{$0.00 *$} \\
\hline $3.1-3.5 \mathrm{~kg}$ & $51(22.2 \%)$ & 37 (33.0\%) & \\
\hline $3.6-4 \mathrm{~kg}$ & $130(56.5 \%)$ & $53(47.3 \%)$ & \\
\hline$>4 \mathrm{~kg}$ & $04(1.7 \%)$ & $06(05.4 \%)$ & \\
\hline Total & $230(100.0)$ & $112(100 \%)$ & \\
\hline \multicolumn{4}{|l|}{ Fetal gender } \\
\hline Male & $102(44.3 \%)$ & $60(53.6 \%)$ & \multirow{3}{*}{$0.02^{*}$} \\
\hline Female & $128(55.7 \%)$ & $52(46.4 \%)$ & \\
\hline Total & $230(100.0 \%)$ & $112(100.0 \%)$ & \\
\hline \multicolumn{4}{|l|}{ Inter pregnancy interval } \\
\hline$<18$ months & $88(38.3 \%)$ & 66 (58.9\%) & \multirow{3}{*}{$0.02^{*}$} \\
\hline$>18$ months & $142(61.7 \%)$ & $46(41.1 \%)$ & \\
\hline Total & $230(100.0 \%)$ & $112(100.0 \%)$ & \\
\hline
\end{tabular}

*Statistically significant at 0.05 level.

between (31-35) were 26 (7.6\%) and more than 35 were 39 (11.4\%).

Previous successful VBAC were revealed in 138 (40.4\%) of women and no previous successful VBAC were 204 (59.6\%). The mean \pm SD of fetal weight was $3.8+1.5 \mathrm{~kg}$.

The study showed a significant correlation between successful rate of VBAC and following factors, regular ante natal care, meticulous counseling, prior vaginal delivery, previous success VBAC, maternal age $<35$ years, increased parity, body mass index (20-25), birth weight less than $4 \mathrm{~kg}$, inter pregnancy interval $>2$ years, female fetus and nonrecurrent indications, such as mal presentation birth and APH (Table 2).

\section{Discussion}

Vaginal Birth after Cesarean Section (VBAC) has been strongly advocated, resulting in a significant increase in attempted and successful vaginal births and a decreasing overall cesarean section rate. However, recently, some cautions have been raised surrounding complications such as uterine rupture or uterine dehiscence that may occur with VBAC and, as such, VBAC rates have declined.

VBAC is becoming a standard of practice in all obstetrical institution around the globe, the success rate of trial of vaginal birth after one previous cesarean section have been reported to be $70-80 \%$ [5-7].

The study revealed that (67.3\%) success rate of VBAC which is comparable with previous studies and the globe standard $[8,9]$.

The current study demonstrated that ,there is significant decline in the success rate of VBAC with increase maternal age and revealed only (5.6\%) of women $>40$ years had success VBAC compared with (49.6\%) success rate among women age between 20-30 years. This finding is similar with studies done by Wing DA who reported that after adjusting for confounding factors, women older than 40 years who have had a prior cesarean delivery have an almost 3-fold higher risk for a failed trial of labor compared with women younger than 40 years. In one scoring system, women younger than 40 years were given an extra point as a predictor for successful VBAC [10]. Bujoldeta also reported from their14year study covering 2493 women that maternal age at the time of TOL equal or greater than 35 years old was associated with a lower rate of successful vaginal delivery (OR: 0.73, 95\% CI: 0.56-0.94) [10].

Our study found low rates of success VBAC with increase maternal BMI and only (2.6\%) success rate of VBAC for women more $>35$ BMI.

While previous studies have evaluated pre pregnancy weight and height to examine the effect on mode of delivery, all of which show that women in the morbidly obese range have a higher risk of failing a trial of labor [11].

In one study of 510 women with a single C/S, women with prepregnancy $\mathrm{BMI} \geq 30$ were less likely to experience VBAC compared to women with a BMI of 20-25 (546/1000 vs. 705/1000). Women with BMI $<19.8$ were most likely to experience a planned VBAC (850/1000). After controlling for other factors, including recurring indications for $\mathrm{C} / \mathrm{S}$, increasing BMI was significantly associated with a lower rate of vaginal birth [12].

The present study revealed higher likelihood of success VBAC among women who have had at least one success VBAC. Again our study match meta- analysis performed by Guise et al who concluded that women with prior VBAC were three to seven times more likely to have a VBAC for their current delivery, compared to women choosing VBAC who had not had a prior vaginal delivery [13]. 
Women with neonatal weights exceeding $4 \mathrm{~kg}$ in our study had less chances of successful VBAC compared to those having neonatal weights $<4 \mathrm{~kg}$. A similar result was obtained by another studies in which it was concluded that the chances of vaginal delivery decreased as the fetal weight exceeded 3.5 $\mathrm{kg}(\mathrm{P}<0.05)[8,9]$.

Success rates also varied according to the indications for the primary caesarean section. The present study revealed that, women with a history of emergency caesarean section were more likely to fail a VBAC than women who had an elective caesarean for their first birth Women with a history of failure to progress were amongst the least likely to succeed with a VBAC. VBAC was maximally successful in patients who were operated previously for non-recurrent indications such as mal presentations. Our study comparable with several studies which have examined indications for prior cesarean delivery as a predictor of outcome in a subsequent trial of labor. In all studies, Failure to progress, CPD, or dystocia as indications for prior cesarean delivery are also associated with a higher proportion of patients not succeed a trial of labor after cesarean birth [14].

In a meta-analysis of the existing literature prior to 1990, Rosen et al demonstrated that women whose prior cesarean delivery was performed for CPD were twice as likely to have an unsuccessful trial of labor [15].

The timing between pregnancies has recently become an interesting predictor for a number of obstetric outcomes, VBAC success among them. In the present study, women who had an inter pregnancy interval of more than 18 months had an (61.7\%) chance of VBAC success, while women whose inter pregnancy interval was less than 18 months had a VBAC success rate of (38.3\%). Chhabra reported [16], that an inter conception period of $<19$ months was associated with low success rate and adverse outcome of VBAC [16].

\section{Conclusion}

The study concludes that a significant increase in the successful rate of VBAC associated with accurate prior ante natal care, meticulous counseling, prior vaginal delivery, previous success VBAC, maternal age $<35$ years, increased parity, body mass index (25-30), birth weight less than $4 \mathrm{~kg}$, inter pregnancy interval $>2$ years, female fetus and nonrecurrent indications, such as mal presentation and $\mathrm{APH}$.

\section{References}

1. American College of Obstetricians and Gynecologists (ACOG): ACOG Practice Bulletin: vaginal birth after previous cesarean delivery: Clinical management guidelines. Int J Gynecol Obstet. 2004; 54: 197-204.
2. Landon MB. vaginal birth after cesarean delivery: 2008; 35: 491-504

3. Royal College of Obstetricians and Gynaecologists (RCOG). Birth after previous caesarean section. Green-Top Guideline No. 45. London: RCOG; 2007.

4. American College of Obstetricians and Gynecologists (ACOG). Vaginal Birth after Previous Cesarean Delivery. Washington, DC: ACOG. 2010.

5. Vogel JP, Betrán AP, Vindevoghel N, Souza JP, Torloni MR, Zhang J, et al. WHO multi-country survey on maternal and newborn Health Research network: use of the Robson classification to assess caesarean section trends in 21 countries: a secondary analysis of two WHO multicounty surveys. Lancet Glob Health. 2015; 3: e260-e270.

6. Ezechi OC, Nwokoro C, Kalu BKE, Njokanma FO, Okeke GCE. Caesarean morbidity and mortality in a private hospital in Lagos Nigeria. Trop J Obstet Gynaecol. 2002; 19: 97-100.

7. Frass KA, A-I-Herazi AH. Outcome of vaginal birth after caesarean section in women with one previous section and spontaneous onset of labor. East Mediterr Health J. 2012; 17: 646-650.

8. BujoldE, HammoudAO, Hendlerl, Berman S, Blackwell SC, Duperron L, etal. Trial of labor inpatients with previous cesarean section: does maternalage in fluence outcome?. Am J Obstet Gynecol. 2004; 190: 1113-1118.

9. Shakti V, Behera RC, Sandhu G Setal, Bandhu HC. Vaginal birth after cesarean delivery. J Obstet Gynecol India. 2006; 56: 320-323.

10. Wing DA, Lovett K, Paul RH. Disruption of prior uterine incision following misoprostol for labor induction in women with previous cesarean delivery. Obstet Gynecol. 1998; 91: 828-830.

11. Lydon-Rochelle M, Holt VL, Easterling TR, Martin DP. Risk of uterine rupture during labor among women with a prior cesarean delivery. $\mathrm{N}$ Engl J Med. 2001; 345: 3-8.

12. Durnwald CP, Ehrenberg HM, Mercer BM. The impact of maternal obesity and weight gain on vaginal birth after cesarean section success. American Journal of obstetrics \& gynecology. 2004; 191: 954-957.

13. Guise JM, Eden K, Emeis C, Denman MA, Marshall N, Fu RR, et al. Vaginal birth after cesarean: new insights. Evid rep technol assess (Full rep). 2010; 191: 1-397.

14. ShaktiV, BeheraRC, Sandhu G Setal. Vaginal birth after cesarean delivery. J Obstet Gynecol India. 2006; 56: 320-323.

15. Rosen MG, Dickinson JC, Westhoff CL. Vaginal birth after cesarean: a metaanalysis of morbidity and mortality. Obstet Gynecol. 1991; 77: 465-470.

16. ChhabraS, Arora G. Delivery in women with previous cesarean section. J Obstet Gynecol India. 2006; 56: 304-307.
Austin J Obstet Gynecol - Volume 5 Issue 9 - 2018 Submit your Manuscript | www.austinpublishinggroup.com Handady et al. (C) All rights are reserved
Citation: Bashir JA, Noureldin K, Elhassan MAY, Abdelwahid MA and Handady MOS. Factors Associated with Success Rate of Vaginal Birth after One Caesarean Section (Vbac) in Ibrahim Malik Teaching Hospital, Khartoum-Sudan. Austin J Obstet Gynecol. 2018; 5(9): 1129. 